Robert G. Hahn MD PhD, Mona Resby MD

\title{
Volume kinetics of Ringer's solution and dextran 3\% during induction of spinal anaesthesia for Caesarean section
}

Purpose: To study how the body handles fluid given intravenously during the onset of spinal anaesthesia in women scheduled for Caesarean section.

Methods: The effect of spinal anaesthesia on the volume kinetics of a constant-rate infusion of $25 \mathrm{ml} \cdot \mathrm{kg}^{-1}$ of Ringer's solution $(n=1 \mathrm{I})$ and $10 \mathrm{ml} \cdot \mathrm{kg}^{-1}$ of dextran $3 \% 60(n=8)$ was studied before elective Caesarean section. Measurements of the blood haemoglobin concentration and urine excretion served as input variables in calculations of the size(s) of the body fluid spaces expanded by the infused fluid. The blood glucose level was also monitored.

Results: When a one-volume kinetic model were fitted to the data, spinal anaesthesia reduced the size of the expanded body fluid space by $30 \%$ (Ringer's) and $58 \%$ (dextran) $(P<0.02)$ When a two-volume model was statistically justified, anaesthesia reduced the rate of fluid equilibration between the two expanded body fluid spaces by $47 \%$ and $19 \%$, respectively $(P<0.04)$ The baseline volume for the primary (central) fluid space was smaller than the expected plasma volume; 1.5 I for Ringer's solution and 0.91 for dextran. Only small changes in the blood glucose concentration were found.

Conclusion: The onset of spinal anaesthesia induces acute changes in the body's handling of infused fluid that can be described by volume kinetic analysis.

Objectif : Étudier le devenir des liquides administrés par voie intraveineuse durant l'induction de l'anesthésie rachidienne chez des parturientes subissant une césarienne.

Méthodes : Les effets de la rachianesthésie sur la cinétique volumétrique d'une infusion à débit constant de 25 $\mathrm{ml} \cdot \mathrm{kg}^{-1}$ de solution de Ringer $(n=11)$ ou de $10 \mathrm{ml} \cdot \mathrm{kg}^{-1}$ de dextran 60 en solution à $3 \%(n=8)$ ont été étudiés avant la césarienne élective. Les mesures du taux d'hémoglobine sanguin et du débit urinaire ont senvi comme entrées variables dans le calcul de l'expansion volémique par le liquide infusé des différents compartiments corporels. La glycémie a aussi été mesurée.

Résultats : Lorsque les données étaient rapportées à un modèle cinétique à un seul compartiment, l'anesthésie rachidienne entrainait une réduction du compartiment corporel déjà distendu de $30 \%$ pour le Ringer et de $58 \%$ pour le dextran $(P 0,02)$. Lorsqu'un modèle à deux compartiments apparaissait justifié d'un point de vue statistique, l'anesthésie entraînait une réduction du taux d'équilibration entre les deux compartiments corporels déjà distendus de $47 \%$ et de $19 \%$ respectivement $(P 0,04)$. Le volume de base pour le compartiment primaire (central) était plus petit que le volume plasmatique prévu: 1,5L pour le Ringer et $0,9 \mathrm{~L}$ pour le dextran. La glycémie a peu varié.

Conclusion : Linduction de l'anesthésie rachidienne entraine des modification aiguës de la gestion par le corps humain des liquides infusés, ces modifications pouvant être décrites par des analyses de cinétique volumétrique.

From the Department of Anesthesia, Karolinska Institute, Department of Anaesthesia, Söder Hospital, S-118 83 Stockholm, Sweden. Address correspondence to: Professor Robert G. Hahn; Fax: 46-8-616-22-34; E-mail: Robert.Hahn@anest.sos.sll.se Accepted for publication January 31, 1998. 
A CUTE hydration is a part of the prophylaxis of maternal hypotension during onset of spinal anaesthesia for Caesarean section. Large amounts of crystalloid ${ }^{1-3}$ or colloid solution ${ }^{3-6}$ are given to increase the blood and interstitial fluid volumes. It is common to infuse $15-25 \mathrm{ml} \cdot \mathrm{kg}^{-1}$ Ringer's solution for this purpose ${ }^{2-6}$ while only half as much colloid is needed because it expands the blood volume more effectively. ${ }^{4-6}$ Arterial hypotension is common in the mother, however, regardless of the quality and quantity of fluid given. The poor preventive effect is difficult to explain as hypovolaemia is believed to be the cause of the hypotension.

To understand better why fluid is not particularly helpful, we have used a kinetic model to outline how the body handles Ringer's solution and dextran 3\% under these conditions. The kinetic approach is based on the assumption that fluid given by intravenous infusion expands either one ( $V$ ) or two $\left(V_{1}\right.$ and $\left.V_{2}\right)$ fluid spaces in the body. The elimination of fluid from the system and the exchange of infused fluid between $V_{1}$ and $V_{2}$ are governed by the constants $k_{\mathrm{r}}$ and $k_{\mathrm{t}}$, respectively. ${ }^{7-11}$

Repeated measurements of the blood haemoglobin (B-Hb) concentration and urinary excretion were used by a computer to find estimates of the parameters in the volume kinetic models. We also measured the blood glucose level, as it is possible that hypoglycaemia aggravates the hypotension and makes it more difficult to reverse. ${ }^{12}$

\section{Patients and methods}

We studied 19 healthy women aged between 24 and $42 \mathrm{yr}$ (mean $35 \mathrm{yr}$ ) with a body weight of $58-96 \mathrm{~kg}$ (mean $74 \mathrm{~kg}$ ) scheduled for elective Caesarean section. The gestational week ranged between 37 and 40 . The protocol was approved by the Local Ethics Committee and the informed consent of all women was obtained.

\section{Procedure}

After an overnight fast, all women underwent surgery which started between 8 and $10 \mathrm{am}$. Before any fluid was administered, a cannula was placed in the antecubital vein of each arm for sampling blood and infusing fluid. They were randomly allocated to receive an intravenous (iv) fluid load of either $25 \mathrm{ml} \cdot \mathrm{kg}^{-1}$ Ringer's acetate solution ( $n=11$; Pharmacia, Uppsala, Sweden) or $10 \mathrm{ml} \cdot \mathrm{kg}^{-1}$ dextran $603 \%$ in Ringer's solution $(\mathrm{n}=8$; Medisan, Uppsala, Sweden). The Ringer's solution had the following ionic content: $\mathrm{Na} 130, \mathrm{~K} 4, \mathrm{Ca} 2, \mathrm{Mg} \mathrm{l}$, Cl 110 and acetate $30 \mathrm{mmol} \cdot \mathrm{l}^{-1}$. Each dextran infusion was preceded by $20 \mathrm{ml}$ hapten inhibitor (Promiten $^{\circledR}$,
Medisan, Uppsala, Sweden) iv to prevent dextraninduced anaphylactoid reactions.

The fluids were given at a constant rate over $45 \mathrm{~min}$ via an infusion pump (Flo-Gard 6201, Baxter Healthcare, Deerfield, IL, USA). After $25 \mathrm{~min}$, spinal anaesthesia was induced using 2-3 $\mathrm{ml}$ hyperbaric bupivacaine $0.5 \%$ (Marcaine ${ }^{\circledast}$, Astra, Södertälje, Sweden). Immediately after injection, the patient was turned from the lateral to the supine position, but with a left uterine displacement, and was given $10 \mathrm{mg}$ ephedrine $i \mathrm{p}$.

Monitoring included pulse oximetry and electrocardiography. Blood pressure was measured, on the arm not used for infusion, every two minutes by a mercury sphygmomanometer and a stethoscope by one of the researchers. Additional doses of $5 \mathrm{mg}$ ephedrine $i p$ were given if required to keep the systolic arterial pressure $>90 \mathrm{mmHg}$. The Apgar score was recorded at 1, 5 and $10 \mathrm{~min}$ after delivery.

\section{Measurements}

Venous blood $(0.5 \mathrm{ml})$ was collected every two minutes for $46 \mathrm{~min}$, i.e., during the entire infusion of fluid. A small discard sample was drawn prior to each blood collection to preclude blood remaining in the cannula from the previous sampling of the analysis. The $\mathrm{B}-\mathrm{Hb}$ and B-glucose concentrations were measured immediately after each sampling using portable HemoCue photometers (HemoCue Ltd., Ängelholm, Sweden) brought into the operating theatre. The coefficient of variation is specified as being $2 \%$ for $\mathrm{B}-\mathrm{Hb}$ and $4 \%$ for glucose. The first sample was drawn in duplicate and the mean value was used. Urine excretion from an indwelling urinary catheter was measured continuously.

\section{Calculations}

The distribution of the fluid given by intravenous infusion was analysed using volume-of-fluid-spaces kinetic models, which can be summarised as follows (Figure 1, top).

In the one-volume model, fluid given by intravenous infusion at a rate $k_{i}$ is distributed in an expand able space with a volume $(v)$, which the fluid space strives to maintain at a target (baseline) volume $(V)$. Fluid leaves the space at a basal rate $\left(k_{b}\right)$ and at a controlled rate proportional, by a constant $\left(k_{r}\right)$, to the deviation from the target volume. In the two-volume model, the primary fluid space communicates with a secondary fluid space. The rate of volume equilibration between the expandable fluid spaces (with volumes $v_{1}$ and $v_{2}$ ) is proportional to the relative difference in deviation from the target values ( $V_{1}$ and $V_{2}$ ) by a constant $\left(k_{\mathrm{t}}\right)$ (Figure 1 , bottom). The differential equations describing the volume changes in the 
expanded body fluid spaces as well as their matrix solutions are given in the Appendix.

Several modifications of these models were made to adapt them to the situation studied. During ongoing infusion of fluid, but not without it, ${ }^{13}$ epidural ${ }^{13,14}$ and spinal anaesthesia ${ }^{15}$ markedly change the dilution of the blood. This dilution was assumed to represent either a change in the size of the target volume (onevolume model) or a change in $k_{t}$ (two-volume model). Urine excretion was used together with the integral of the dilution-time curve to calculate the elimination rate constant $k_{\mathrm{r}}$, both for the time until the spinal anaesthesia was induced and for the period thereafter. ${ }^{11}$ The values obtained for $k_{\mathrm{r}}$ were then used as input data in the volume kinetic analysis to improve model stability. Previously, $k_{\mathrm{r}}$ has been determined by the analysis, but the model-predicted urinary excretion agrees well with the measured volume. ${ }^{8}$

The plasma dilution, i. e. $\left(p_{1}-V_{1}\right) / V_{1}$, was used to quantitate the fluid load. This was taken as the product of ( 1 - baseline haematocrit) and the dilution of the B-Hb level, as the erythrocytes represent an intracellular fluid space not expanded by Ringer's solution or dextran. Correction for the loss of erythrocytes during the blood sampling was made ${ }^{16}$ based on an estimated preoperative blood volume of $83.3 \mathrm{ml} \cdot \mathrm{kg}^{-1}$

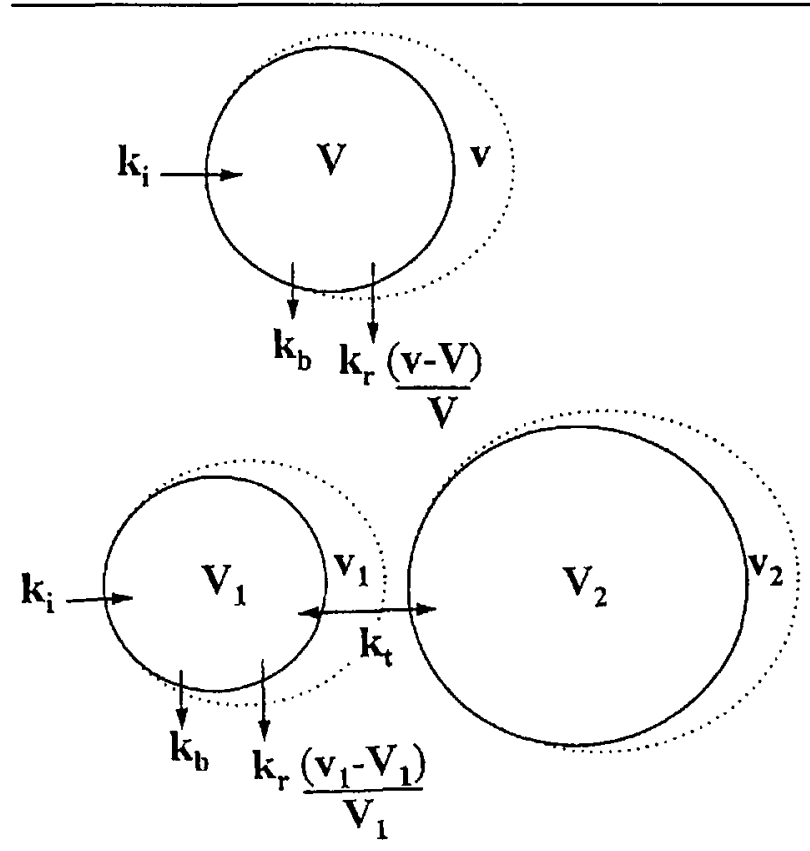

FIGURE I Schematic drawing of the one-volume kinetic model (top) and the two-volume kinetic model (bottom) used to calculate the size of the body fluid space expanded by intravenous infusion of fluid in humans. body weight. ${ }^{17}$ The model parameters were computed using Matlab version 4.2 (Math Works Inc., Notich, Mass., USA) whereby a non-linear least-squares regression routine based on a modified Gauss-Newton method was repeated until no parameter changed by more than $0.001(0.1 \%)$ in each iteration. The output consisted in the best estimate and the standard error (SE) for $V$ before and after induction (one-volume model) and for $V_{1}$ and $V_{2}$ as well as $k_{\mathrm{t}}$ before and after induction (two-volume model). The results of the two-volume model analysis were reported only if an $F$ test indicated that it was statistically justified. ${ }^{11}$ In all analyses, $k_{\mathrm{b}}$ was set to $0.5 \mathrm{ml} \cdot \mathrm{min}^{-1}(700 \mathrm{ml}$ per $24 \mathrm{~h}$ ) which is a reasonable estimation of the basal fluid loss (insensible water loss and diuresis) from the expanded fluid space. ${ }^{9,18}$

Several individual curves were impossible to analyse according to the two-volume model as they did not yield a stable value for $V_{2}$. This volume sometimes became unrealistically large, was estimated with poor precision and correlated strongly with $k_{\mathrm{r}}$. Therefore, the individual curves were analysed after using fixed value of $V_{2}$ assuming that the sum of $V_{1}$ and $V_{2}$ is equal to $15 \%$ (Ringer's) and $7.5 \%$ (dextran $3 \%$ ), respectively, of the patient's body weight. ${ }^{8,11}$ The figure used for dextran $3 \%$ was taken to be half-way between that previously obtained for dextran $6 \%$ and Ringer's solution. ${ }^{9}$

Differences with respect to patient group and whether or not spinal anaesthesia had been induced were studied by repeated-measures (two-way) analysis of variance. Correlations between parameters were evaluated by linear regression analysis. $P<0.05$ was considered statistically significant.

\section{Results}

The age and gestational week was the same for the women who received Ringer's solution as for those who were given dextran (Table I). The body weight tended to be higher in the dextran group, but this difference was not significant.

TABLE I Demographic data in 19 women scheduled for Caesarean section. The mean and range are given.

\begin{tabular}{lll}
\hline & $\begin{array}{l}\text { Ringer's solution } \\
(n=11)\end{array}$ & $\begin{array}{l}\text { Dextran 3\% } \\
(n=8)\end{array}$ \\
\hline Age (yr) & $35(24-42)$ & $35(29-39)$ \\
Body weight $(\mathrm{kg})$ & $70(58-96)$ & $79(67-93)$ \\
Gestational week & $38.1(37-39)$ & $38.5(38-40)$ \\
Fluid volume infused (1) & $1.71(1.44-1.93)$ & $0.79(0.67-0.93)$ \\
\hline
\end{tabular}



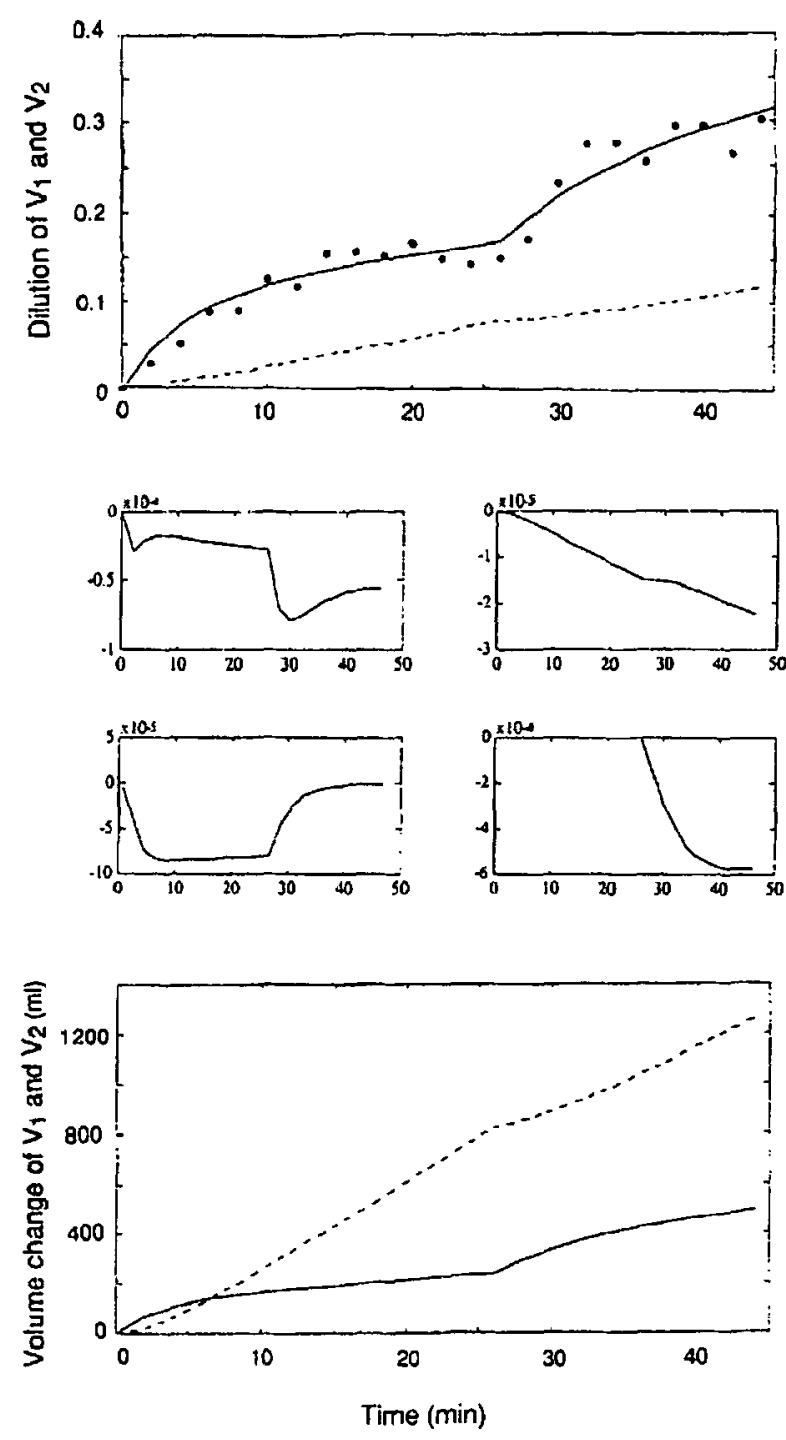

FIGURE 2 Volume kinetic analysis for Ringer's acetate based on application of the two-volume model to the mean data from 11 patients. Spinal anaesthesia was induced at $25 \mathrm{~min}$.

Top: The measured dilution of the plasma volume (points) and the modelled dilution of $V_{1}$ (solid line) and $V_{2}$ (broken line). The parameter estimates were:

$V, 1.37 \mathrm{l} ; V_{2} 10.7 \mathrm{l} ; k_{\mathrm{t}} 367$ and $127 \mathrm{ml} \cdot \mathrm{min}^{-1}$, respectively. Middle section: Sensitivity curves, where the distance of the line from zero indicates the relative contribution of that time segment to the value of the kineric parameters $V_{1}$ (upper left) and $V_{2}$ (upper right)

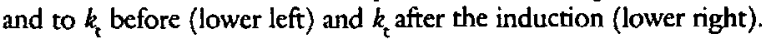
Bottom: The modelled volume changes of $V_{l}$ (solid line) and $V_{2}$ (broken line).

\section{Volume kinetics}

The mean plasma dilution was practically the same with the two infusions (Figures 2 and 3, top). When the dilution-time profiles were analysed according to the one-volume model, the target volume for the fluid
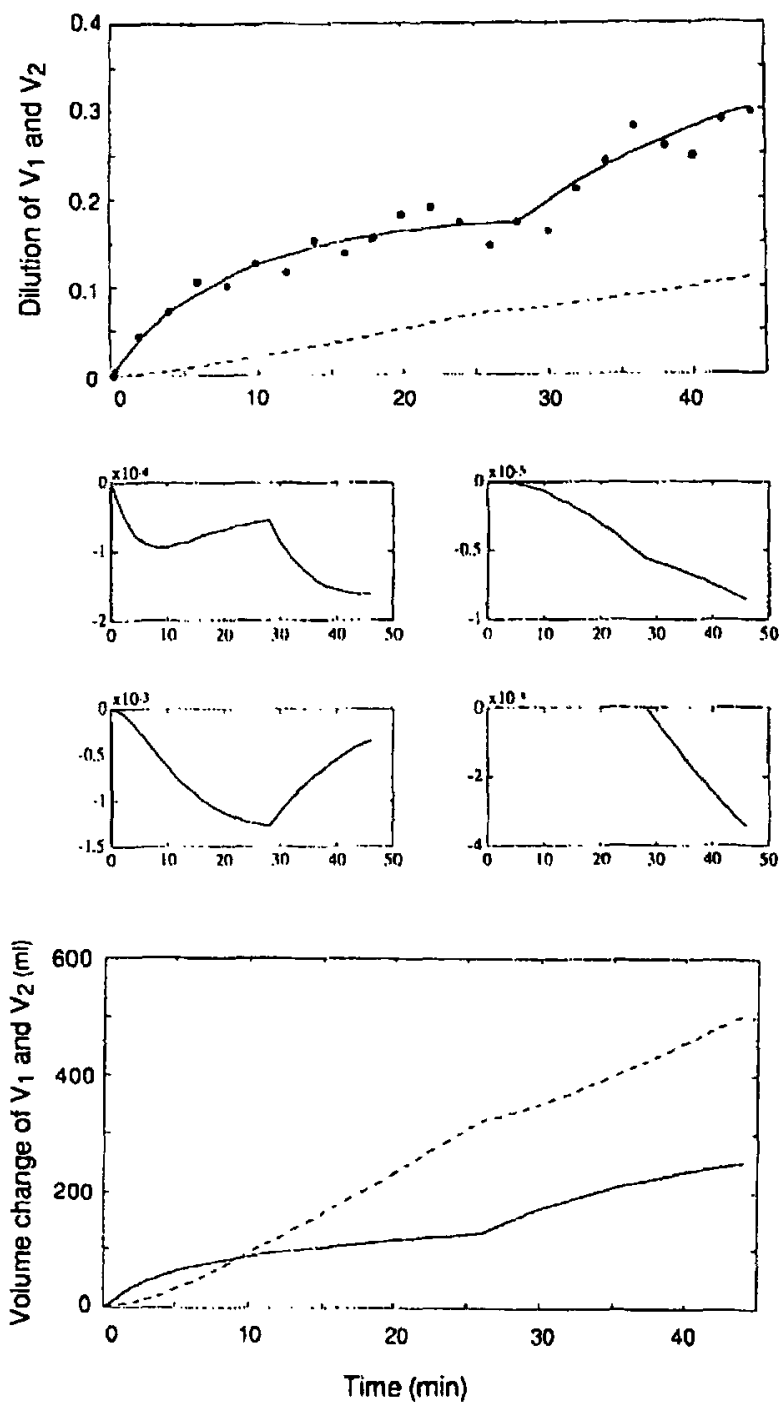

FIGURE 3 Volume kinetic analysis for dextran $603 \%$. For Legends, see Figure 2. The parameter estimates were: $V_{1} 0.79 \mathrm{l} ; V_{2} 7.0 \mathrm{l} ; k_{\mathrm{r}} 112$ and $38 \mathrm{ml} \cdot \mathrm{min}^{-1}$, respectively.

space expanded by the infused fluid $(V)$ was smaller after spinal anaesthesia had been induced $(P<0.02$; Table II). The mean reductions were $30 \%$ (Ringer's) and $58 \%$ (dextran), respectively: $V$ seemed to be smaller when dextran was infused, but this difference did not reach statistical significance $(P=0.07$; repeatedmeasures ANOVA).

The experiments for which the two-volume model was statistically justified showed higher values for $k_{\mathrm{t}}$ when Ringer's was used $(P<0.01)$. The onset of anaesthesia reduced $k_{t}$ by $47 \%$ (Ringer's) and 19\% (dextran), respectively $(P<0.04$; Table II). 
TABLE II Results of the volume kinetic analysis before and after induction of spinal anaesthesia in 19 women.

\begin{tabular}{|c|c|c|}
\hline & Ringer's solution & Dextran 3\% \\
\hline One-volume model & $\mathrm{n}=4$ & $n=4$ \\
\hline \multirow[t]{2}{*}{$V$ before induction (l) } & $6.25 \pm 0.61$ & $3.88 \pm 0.92$ \\
\hline & $1.55 \pm 0.25$ & $0.78 \pm 0.21$ \\
\hline \multirow[t]{2}{*}{$V$ after induction ( 1 ) } & $4.35 \pm 1.44$ & $1.64 \pm 0.32$ \\
\hline & $1.87 \pm 0.45$ & $0.41 \pm 0.08$ \\
\hline Sun of squared errors $\left(10^{-3}\right)$ & $59 \pm 19$ & $24 \pm 9$ \\
\hline$k_{\mathrm{r}}$ before induction $\left(\mathrm{ml} \cdot \mathrm{min}^{-1}\right)$ & $34 \pm 10$ & $28 \pm 11$ \\
\hline$k_{\mathrm{r}}$ after induction $\left(\mathrm{ml} \cdot \mathrm{min}^{-1}\right)$ & $21 \pm 10$ & $4 \pm 1$ \\
\hline Urinary excretion (total, $\mathrm{ml}$ ) & $163 \pm 36$ & $63 \pm 16$ \\
\hline Two-volume model $l^{*}$ & $\mathrm{n}=7$ & $n=4$ \\
\hline \multirow[t]{2}{*}{$k_{\mathrm{t}}$ before induction $\left(\mathrm{ml} \cdot \mathrm{min}^{-1}\right)$} & $420 \pm 92$ & $108 \pm 43$ \\
\hline & $134 \pm 46$ & $47 \pm 8$ \\
\hline \multirow[t]{2}{*}{$k_{\mathrm{r}}$ after induction $\left(\mathrm{ml} \cdot \mathrm{min}^{-1}\right)$} & $221 \pm 38$ & $88 \pm 22$ \\
\hline & $57 \pm 14$ & $35 \pm 8$ \\
\hline \multirow[t]{2}{*}{$V_{1}$ before and after induction (l) } & $1.44 \pm 0.21$ & $0.88 \pm 0.50$ \\
\hline & $0.68 \pm 0.15$ & $0.50 \pm 0.05$ \\
\hline Sun of squared errors $\left(10^{-3}\right)$ & $25 \pm 5$ & $48 \pm 9$ \\
\hline$k_{\mathrm{r}}$ before induction $\left(\mathrm{ml} \cdot \mathrm{min}^{-1}\right)$ & $8 \pm 3$ & $16 \pm 6$ \\
\hline$k_{\mathrm{r}}$ after induction $\left(\mathrm{ml} \cdot \mathrm{min}^{-1}\right)$ & $15 \pm 7$ & $14 \pm 4$ \\
\hline Urinary excretion (total, $\mathrm{ml}$ ) & $82 \pm 27$ & $101 \pm 31$ \\
\hline
\end{tabular}

The first line for each parameter obtained by a curve-fitting procedure gives the estimate and the second line gives its standard error The elimination rate constant $\left(k_{r}\right)$ was calculated from the urinary excretion. In parenthesis after each mean value is the variability for the group expressed as the standard error of the mean \pm SEM.

${ }^{*} V_{1}+V_{2}$ was assumed to be $15 \%$ (Ringer's) or $7.5 \%$ (dextran) of the body weight.

The two-volume model fitted to the mean plasma dilution-time data (Figures 2 and 3, top) yielded sensitivity curves and volume-time profiles typical of these experiments (Figures 2 and 3, bottom). Ringer's solution hydrated $v_{2}$ much more than dextran did. With both fluids, the hydration of $v_{2}$ continued after spinal anaesthesia had been induced.

\section{Haemodynamics and blood glucose}

Induction of anaesthesia was followed by an increase in heart rate and a decrease in mean arterial pressure $(P<0.001$; Table III). Three of the women who received Ringer's solution required $20 \mathrm{mg}$ additional ephedrine, while only one woman in the dextran group was given additional ephedrine $(5 \mathrm{mg})$. The sensory block extended to $T_{3}, T_{4}$ or (in a few cases) $T_{5}$.

The Apgar score at one minute was 9.2 (mean; range 6-10) in the Ringer's group and 9.3 (9-10) in the dextran group. All children had Apgar scores of 10 at 5 and $10 \mathrm{~min}$ after delivery.

Induction of spinal anaesthesia slightly increased the blood glucose level, particularly when the haemodilu-
TABLE III Haemodynamics and blood glucose during volume loading and spinal anaesthesia before Caesarean section.

\begin{tabular}{|c|c|c|}
\hline & $\begin{array}{l}\text { Ringer's solution } \\
(n=11)\end{array}$ & $\begin{array}{l}\text { Dextran 3\% } \\
(n=8)\end{array}$ \\
\hline \multicolumn{3}{|l|}{ Heart rate (bpm) } \\
\hline Baseline $(0 \mathrm{~min})$ & $85(79-92)$ & $84(76-92)$ \\
\hline Before induction (2-24 min) & $88(85-91)$ & $87(85-89)$ \\
\hline Onset of anaesthesia (26 min) & $92(80-105)$ & $95(81-109)$ \\
\hline Spinal anaesthesia $(28-46 \mathrm{~min})$ & $95(90-100)$ & $102(97-106)$ \\
\hline \multicolumn{3}{|l|}{$\begin{array}{l}\text { Mean arterial } \\
\text { pressure (mmHg) }\end{array}$} \\
\hline Baseline & $98(91-105)$ & $93(90-97)$ \\
\hline Before induction & $98(96-99)$ & $96(95-97)$ \\
\hline Onset of anaesthesia & $98(89-107)$ & $93(83-102)$ \\
\hline Spinal anaesthesia & $93(83-100)$ & $90(86-94)$ \\
\hline \multicolumn{3}{|l|}{ Blood glucose $\left(\right.$ mmol. $\left.\mathrm{H}^{-1}\right)$} \\
\hline Baseline & $4.02(3.83-4.20)$ & $3.90(3.51-4.29)$ \\
\hline Before induction & $4.00(3.93-4.08)$ & $3.89(3.78-4.00)$ \\
\hline Onset of anaesthesia & $4.13(3.80-4.47)$ & $4.14(3.42-4.85)$ \\
\hline Spinal anaesthesia & $4.05(3.94-4.15)$ & $4.07(3.90-4.24)$ \\
\hline
\end{tabular}

The mean value for the time period before and after the induction of spinal anaesthesia was first calculated. The mean and $95 \%$ confidence interval for these data in all patients are given.

Measurements were performed every two minutes.

Spinal anaesthesia was induced after $25 \mathrm{~min}$.

tion was small (Figure 4). More pronounced reductions of the $\mathrm{B}-\mathrm{Hb}$ and blood glucose levels following the induction of spinal anaesthesia were not associated with a reduced Apgar score.

\section{Discussion}

This study was undertaken to capture the dynamics of fluid given intravenously during the induction of spinal anaesthesia in a patient group in which volume loading is controversial. For this purpose, a kinetic model used previously was developed further so that the body's handling of Ringer's acetate and dextran $3 \%$ before and after the onset of anaesthesia could be compared. The modifications of the one-volume and the two-volume models introduced here were made to highlight the change in fluid kinetics resulting from the spinal anaesthesia. The choice of fluids and the amounts infused were governed by other studies of Caesarean section ${ }^{2-6}$ and volume kinetics ${ }^{7-11}$ but also by our local practice. In Sweden, dextran 60 in a concentration of $3 \%$ is widely used during surgery and for volume loading, ${ }^{19}$ and acetate is the only buffer used in commercially available Ringer's solutions.

Our results show the body's handling of these fluids undergoes similar changes when spinal anaesthesia is 


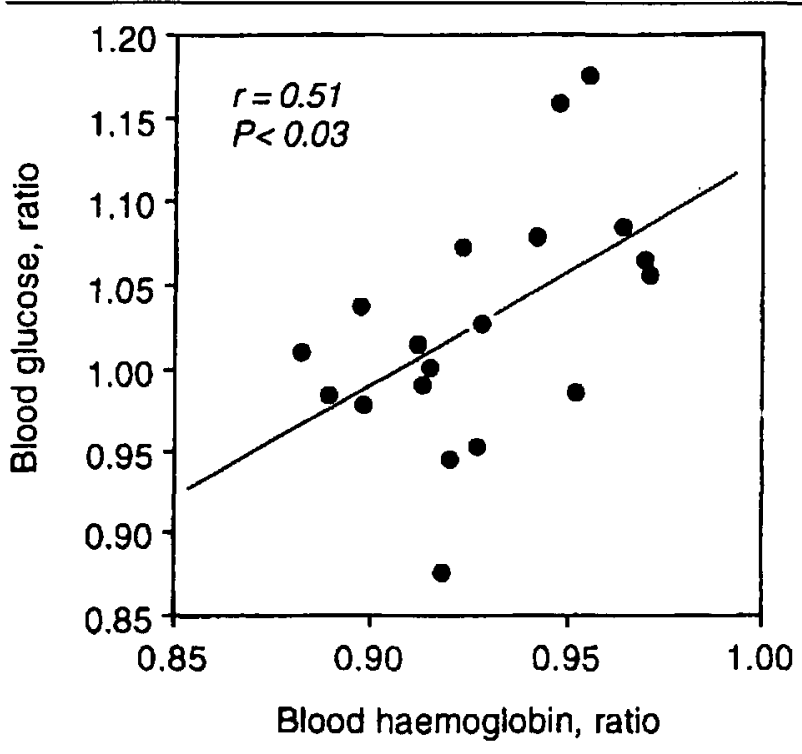

FIGURE 4 The blood glucose concentration versus the hacmodilution. Each point represents one patient. The mean value for all data obtained after the induction of anaesthesia in this patient is divided by the mean value for all data obtained before the induction.

induced. Both fluids accumulate more in the central parts of the body during spinal anaesthesia than before the induction. This effect is expressed differently in the one-volume and the two-volume models. The main measure of outcome in the one-volume model is the expandable fluid space $(V)$ which the body strives to maintain after all the infused fluid has been excreted. ${ }^{7}$ The changes in the dilution of the blood in the cubital vein over time can be used to calculate the size of this volume, which should not be regarded as an anatomical space but as a functional compartment determined by differences in compliance to volume expansion between tissues. For example, a large $V$ implies a widespread distribution of the fluid in the body, resulting in a less pronounced haemodilution provided that the elimination rate constant $\left(k_{r}\right)$ is the same.

The present analyses according to the one-volume model indicates that anaesthesia made the infused fluid expand a smaller $V$ than before the induction. This means that the forces acting to keep the infused fluid in a functional compartment inside or close to the bloodstream outweigh those that allow diffusion of fluid to more peripheral parts of the body. The elimination rate constant tended to be lower in the presence of the spinal anaesthesia, but this was not enough to explain the markedly increased haemodilution that developed after the induction.

A more elaborate analysis is obtained by the twovolume model, which was more correct to use when the experimental dilution-time curves had a clear exponential nature. Here, the induction of spinal anaesthesia could be expected to change the parameter entitled $k_{\mathrm{t}}$, which governs the rate of fluid exchange between the two body fluid spaces that become expanded by the infused fluid. A change in $k_{\mathrm{r}}$ would quantitate the proposed relationship in compliance between the central and the peripheral fluid compartments with regard to volume expansion to the advantage of the central compartment. ${ }^{14,20}$ Our results show that, both with Ringer's and dextran, induction of anaesthesia reduced $k_{\mathrm{t}}$ to between $50 \%$ and $80 \%$ of baseline. Thus, the infused fluid tended to accumulate in the functional fluid space to which the ante-cubital vein blood belongs $\left(v_{1}\right)$ rather than diffusing to the peripheral fluid space $\left(v_{2}\right)$.

An interesting finding is the small size of the target volumes after spinal anaesthesia had been induced. The dextran 3\% solution is designed to expand the plasma volume by half the infused amount of fluid, but the average size of $V$ after the induction was clearly smaller than the expected plasma volume in these pregnant women. In previous reports, fitting the twovolume model to the dilution-time curves obtained during infusion of Ringer's solution in men and nonpregnant women has usually given a target volume for $p_{1}$ (denoted $V_{1}$ ) that is close to the expected plasma volume. ${ }^{8,9}$ However, $V_{1}$ was about $1.5 \mathrm{I}$ for Ringer's solution in the present study, which also suggests that fluid infused during onset of spinal anaesthesia accumulates primarily in a smaller part of the vascular bed. Although we believe that the total plasma volume was probably a part of $V_{1}$ during the initial $25 \mathrm{~min}$ of volume loading, the increased haemodilution developing just after the anaesthesia had been induced was strong enough to give a different interpretation of the dilution-time curve. The sensitivity curves in the middle of Figures 2 and 3 confirm that the relative contribution of the time segment after the induction was very important to the volumes obtained for $V_{1}$.

The small size of $V_{1}$ may be explained by the shifting of blood to the legs, which allows hypovolaemia to develop in the thorax, abdomen and arms. ${ }^{21}$ The vasodilated legs have a relatively slow time constant for venous return ${ }^{22}$ and, from a kinetic point of view, probably become part of the secondary fluid space $\left(v_{2}\right)$. Thus, our findings are consistent with that transient differences in haemodilution develop between different major venous vessels in the body when spinal anaesthesia has just been induced. Further studies are needed to evaluate this hypothesis.

The volume-time curves in Figures 2 and 3 may help to explain why volume loading does not prevent the drop in arterial pressure accompanying spinal anaesthe- 
sia. Volume loading is often carried out on the assumption that an increase in the interstitial hydrostatic pressure will result in a rapid backward diffusion of fluid into the circulation again as soon as a drop in capillary hydrostatic pressure occurs, thereby reducing the magnitude of the hypotension. However, despite the fact that hypovolaemia develops in central body organs when venous return falls, $v_{2}$ continued to expand also after the spinal anaesthesia had been induced. Hence, no backward diffusion of fluid from $v_{2}$ to $v_{1}$ occurred, which confirms results obtained by other methods in elderly patients studied during induction of epidural anaesthesia. ${ }^{13,14,20}$ According to this view, preloading would be expected to be of little help in preventing spinal hypotension. A more rational approach would be to infuse fluid very rapidly just at the onset of the spinal anaesthesia. This regimen is not practical but, still, its effectiveness should be evaluated in the clinic.

Kinetic data are useful in simulations of volume expansion by computer where the effects of different fluid programs on the expandable body fluid spaces can be studied. However, certain aspects of the present data should be considered before using them for simulation experiments. As arterial hypotension is a threat to the well-being of the foetus, we did not consider it safe to withhold ephedrine from our patients. This drug may have slightly modified the reported effects of spinal anaesthesia on the volume kinetics. Ephedrine primarily acts by increasing the cardiac output and, to a lesser extent, by causing vasoconstriction. ${ }^{23}$ If anything, ephedrine could be expected to reduce slightly the peripheral vasodilation resulting from spinal anaesthesia, thereby reducing the excessive haemodilution and, in consequence, the degree of changes in expanded body fluid volumes and rates of fluid exchange. Therefore, we believe that ephedrine did not change the quality but possibly influenced the magnitude of the reported changes. The haemodilution found here, however, was similar to that obtained in male patients in whom ephedrine was not used. ${ }^{14}$

Another point is that the women studied had a remarkably weak diuretic response to volume loading. The urinary excretion would be at least 500 to $600 \mathrm{ml}$ during a similar experiment in non-pregnant women, ${ }^{8}$ but in this study the urine volumes were only one tenth as large. Hence, $k_{\mathrm{r}}$ was very small, and this is why the exponential nature of the data profiles was lost when modelling was done according to the onevolume model. Third, the requirement of high-level analgesia during Caesarean section prevented us from studying variations in the kinetic parameters depending on the extent of analgesia.
We were somewhat disappointed with the HemoCue equipment in this specific blood sampling situation. Its precision was apparently poorer than we have experienced after measuring the $\mathrm{B}-\mathrm{Hb}$ level on blood samples sent to our routine laboratory. ${ }^{9}$ This contributed to high sun of squared errors when the kinetic models were fitted to the data and also to the relatively high standard errors of the parameter estimates. Further studies of volume kinetics should probably be based on duplicate samples and possibly on another photometer.

The precision of the haemoglobin assay highlighted difficulties in estimating the size of $V_{2}$ when the twovolume model was used. In fact, $V_{2}$ could only be estimated when the dilution-time profile represented a fairly smooth curve, such as in Figures 2 and 3. Even in these cases, however, high standard errors indicated that the estimate was so uncertain that it did not contain any real information. The sensitivity curves for $V_{2}$ might serve to explain these problems. The source for the estimation of $V_{2}$ was the entire dilution-time curve but the importance of the data increased with time. The fact that the maximum difference from baseline was reached at the end of the experiment suggests that $V_{2}$ had been easier to estimate if the blood sampling had been carried out for a longer period of time after the anaesthesia had been induced. Such a practice would raise ethical considerations, however, as the operation could not be allowed to start until the sampling period was ended.

The problem with $V_{2}$ was handled by introducing a fixed value for $V_{1}+V_{2}$ with a size that could be expected from previous work. ${ }^{8,9,11}$ Several other figures for the total size of the body fluid space expanded by the infused fluid were used in addition to those reported here, but without qualitative effects on the estimates of $V_{1}$ and $k_{\mathrm{t}}$. Increasing and decreasing the fixed value of $V_{1}+V_{2}$ by $50 \%$ usually changed $V_{1}$ by less than $10 \%$ while the two estimates of $k_{t}$ decreased and increased, respectively, by about the same magnitude as the fixed volume was altered. This would suggest that the size of $V_{1}$ presented in the present study is valid. If another size of $V_{2}$ is assumed, however, the two estimates of $k_{t}$ attain other values while their internal relationship remains quite stable.

Another part of this study was concerned with blood glucose concentration, which is of interest in pregnant women. It is often low during preoperative fasting, ${ }^{12,24,25}$ which may reduce the transport of glucose from the mother to the foetus. ${ }^{26}$ Therefore, any further decrease due to dilution by glucose-free Ringer's solution is undesirable. Some studies, ${ }^{25-27}$ but not all, ${ }^{24}$ have found that volume loading with glucose-free fluid lowered the blood glucose level before Caesarean section. Glucose $5 \%$ has been added to the crystalloid fluid to prevent such dilutional hypoglycaemia, but this results 
in foetal hyperinsulinaemia and hypoglycaemia in the early newborn period. ${ }^{25,27,28}$

This study failed to show any case of hypoglycaemia. Blood glucose concentration decreased with the haemodilution, but induction of anaesthesia seemed to include a hyperglycaemic stimulus. The latter "upward shift" of the glucose curve is probably caused by the adrenergic effect of ephedrine, ${ }^{23}$ which was given to all women. The combined effect of haemodilution and anaesthesia was then a slight increase in the average blood glucose level. As the haemodilution increases with the peripheral vasodilation, a reduction of blood glucose would be expected in patients who develop arterial hypotension during the onset of spinal anaesthesia, particularly when ephedrine is not given. ${ }^{20}$ The hypoglycaemia can then be regarded as evidence of excessive vasodilatation, but according to the present data, it is not associated with a reduced Apgar score as long as the systolic arterial pressure is maintained above $90 \mathrm{mmHg}$.

\section{Acknowledgment}

The used computer programs were designed by Associate Professor Lennart Edsberg, Department of Numerical Analysis and Computing Science, Royal Institute of Technology, Stockholm, Sweden.

\section{Appendix}

The one-volume fluid space model is described by the following differential equation:

$$
\mathrm{d} v / \mathrm{dt}=k_{\mathrm{i}}-k_{\mathrm{b}}-k_{\mathrm{r}} \frac{(v-V)}{V} \quad \text { [Eqn. 1] }
$$

which is solved as a monoexponential solution. Before induction of anaesthesia, it is

$$
\mathrm{w}(\mathrm{t})=\frac{\left(k_{\mathrm{i}}-k_{\mathrm{b}}\right)}{k_{\mathrm{r}}}\left(1-\mathrm{e}^{-k \mathrm{t} / \mathrm{v}}\right) \quad 0 \leq \mathrm{t} \leq \mathrm{t}_{1}
$$

and after (a) induction

$\mathrm{w}_{\mathrm{a}}(\mathrm{t})=\left(\mathrm{w}_{1}(\mathrm{t})-\frac{\left.k_{i}-k_{\mathrm{b}}\right)}{k_{\mathrm{r}}} \mathrm{e}^{-k r(\mathrm{t}-\mathrm{t}) /(\mathrm{V}-\Delta h)}+\frac{k \mathrm{i}-\mathrm{k}_{\mathrm{b}}}{k_{\mathrm{r}}} \mathrm{t}_{1} \leq \mathrm{t} \leq \infty\right.$ [Eqn. 3]

where $\mathrm{w}(\mathrm{t})$ is the dilution $(v(t)-V) / V$ and $\Delta V$ is the change in baseline (target) volume induced by the spinal anaesthesia. $k_{\mathrm{r}}$ is calculated from the measured urine excretion and has different values during and after the induction of the anaesthesia.

The following system of differential equations describes the situation in the two-volume fluid space model:

$$
\begin{aligned}
& \frac{\mathrm{d} v 1}{\mathrm{dt}}=k_{1}-k_{\mathrm{b}}-k_{r} \frac{\left(v_{1}-V_{1}\right)}{V_{1}}-k_{\mathrm{t}} \frac{\left[\left(p_{1}-V_{1}\right.\right.}{V_{1}}-\frac{\left(p_{2}-V_{2}\right]}{V_{1}} \\
& \frac{\mathrm{d} v 2}{\mathrm{dt}}=k_{\mathrm{r}} \frac{\left[\left(p_{1}-V_{1}\right.\right.}{V_{1}}-\frac{\left.\left(v_{2}-V_{2}\right)\right]}{V_{2}}
\end{aligned}
$$

The solution of the two-volume model, [Eqn. 4] and [Eqn. 5], can be presented in different ways. Both an analytical solution ${ }^{7}$ and a matrix solution ${ }^{9}$ have been presented previously. As with the one-volume model, the equations shown here have been adapted for the special situation during spinal anaesthesia. They calculate one $k_{t}$ for the period before and another $k_{t}$ for the period after the anaesthesia has been induced. The form used to present the solution of [Eqn. 4] and [Eqn. 5] is a based on the matrix exponential $\mathrm{e}^{\mathrm{At}}$, which is implemented as a standard function in the mathematical program Matlab. Before anaesthesia, we have

$\left.\left(\begin{array}{c}w_{1}(t) \\ w_{2}(t)\end{array}\right)=\left[\left(k_{1}-k_{b}\right) / K r\right]\left(I-e^{A t}\right)\left(\begin{array}{l}1 \\ 1\end{array}\right) \quad 0 \leq t \leq t\right] \quad$ [Eqn. 6] and after (a) anaesthesia. has been induced, it becomes $\left(\begin{array}{c}w_{1 a}(t) \\ w_{2 a}(t)\end{array}\right)=w_{1}(t) e^{A(t-t))}+\left[\left(k_{1}-k_{b}\right) / k r\left(I-e^{A t}\right)\left(\begin{array}{l}1 \\ 1\end{array}\right) t 1 \leq t \leq[E q n \cdot 7]\right.$ where the matrix $A$ is

$$
\mathrm{A}=\left(\begin{array}{cc}
-(k \mathrm{r}+k \mathrm{t}) / V_{1} & k \mathrm{t} / V_{1} \\
k_{\mathrm{r}} / V_{2} & -k_{\mathrm{r}} / V_{2}
\end{array}\right)
$$

\section{References}

1 Jackson R, Reid JA, Thorburn J. Volume preloading is not essential to prevent spinal-induced hypotension at Caesarean section. Br J Anaesth 1995; 75: 262-5.

2 Rout CC, Akoojee SS, Rocke DA, Gouws E. Rapid administration of crystalloid preload does not decrease the incidence of hypotension after spinal anaesthesia for elective Caesarean section. Br J Anaesth 1992; 68: 394-7.

3 Murray AM, Morgan M, Whitwam JG. Crystalloid versus colloid for circulatory preload for epidural Caesarean section. Anaesthesia 1989; 44: 463-6.

4 Wennberg E, Frid I, Haljamäe $H$, Wennergren $M$, Kjellmer I. Comparison of Ringer's acetate with $3 \%$ dextran 70 for volume loading before extradural Caesarean section. Br J Anaesth 1990; 65: 654-60.

5 Hallworth D, Jellicoe JA, Wilkes RG. Hypotension during epidural anaesthesia for Caesarean section. Anaesthesia 1982; 37: 53-6.

6 Riley ET, Cohen SE, Rubenstein AJ, Flanagan B. Prevention of hypotension after spinal aneschesia for cesarean section: six percent hetastarch versus lactated Ringer's solution. Anesth Analg 1995; 81: 838-42.

7 Stable L, Nilsson A, Habn RG. Modelling the volume of expandable body fluid spaces during i.v. fluid therapy. Br J Anaesth 1997; 78: 138-43. 
8 Habn R G, Drobin D, Ståble L. Volume kinetics of Ringer's solution in female volunteers. $\mathrm{Br} J$ Anaesth 1997; 78: 144-8.

9 Svensén C, Habn RG. Volume kinetics of Ringer solution, dextran 70, and hypertonic saline in male voluntecrs. Anesthesiology 1997; 87: 204-12.

$10 \mathrm{Hahn} \mathrm{RG}$, Svensén C. Plasma dilution and the rate of infusion of Ringer's solution. Br J Anaesth 1997; 79: 64-7.

11 Hahn RG, Drobin D. Urinary excretion as an input variable in volume kinetic analysis of Ringer's solution. Br J Anaesth 1998; 80: 183-8.

12 Marx GF, Domurat MF, Costin M. Potential hazards of hypoglycaemia in the parturient. Can J Anaesth 1987; 34: 400-2.

13 Hahn RG. Haemoglobin dilution from epiduralinduced hypotension with and without fluid loading. Acta Anaesthesiol Scand 1992; 36: 241-4.

14 Drobin D, Habn RG. Time-course of increased haemodilution in hypotension induced by extradural anaesthesia. Br J Anaesth 1996; 77: 223-6.

15 Habn $R G$. Increased haemodilution in hypotension induced by epidural anaesthesia. Acta Anaesthesiol Scand 1993; 37: 357-60.

$16 \mathrm{Habn} \mathrm{RG.} \mathrm{A} \mathrm{haemoglobin} \mathrm{dilution} \mathrm{method} \mathrm{(HDM)}$ for estimation of blood volume variations during transurethral prostatic surgery. Acta Anaesthesiol Scand 1987; 31: 572-8.

17 Ueland $K$. Maternal cardiovascular dynamics. VII. Intrapartum blood volume changes. Am J Obstet Gynecol 1976; 126: 671-7.

18 Guyton $A C$, Hall JE. Textbook of Medical Physiology, 9th ed. Philadelphia: W.B. Saunders Company, 1996: 297-8.

19 Bergman $A$, Andreen $M$, Blombäck $M$. Plasma substitution with $3 \%$ dextran-60 in orthopaedic surgery: influence on plasma colloid osmotic pressure, coagulation parameters, immunoglobulins and other plasma constituents. Acta Anaesthesiol Scand 1990; 34: 21-9.

20 Hahn RG. Origin of intravascular fluid recruited by vasodilatation during epidural anaesthesia. Eur Surg Res 1996; 28: 70-4.

21 Arndt JO, Höck A, Stanton-Hicks M, Stübmeier K-D. Peridural anesthesia and the distribution of blood in supine humans. Anesthesiology 1985; 63: 616-23.

22 Ogilvie RI, Zborowska-Sluis D. Analysis of venous flow transients for estimation of vascular resistance, compliance, and blood flow distribution. Can J Physiol Pharmacol 1987; 65: 1884-90.

23 Innes IR, Nickerson $M$. Norepinephrine, epinephrine, and the sympathomimetic amines. In: Goodman LS, Gilman A (Eds.). The Pharmacoloical Basis of Therapeutics, 5th ed. New York: Macmillan Publishing Co., Inc., 1975: 500-1.
24 Thomas $P$, Buckley $P$, Fox $M$. Maternal and neonatal blood glucose after crystalloid loading for epidural Caesarean section. Anaesthesia 1984; 39: 1240-2.

25 Philipson EH, Kalhan SC, Riba MM, Pimentel $R$. Effects of maternal glucose infusion on fetal acid-base status in human pregnancy. Am J Obstet Gynecol $1987 ; 157 ; 866-73$.

26 Loong EPL, Lao TTH, Chin RKH. Effects of intrapartum intravenous infusion of $5 \%$ dextrose or Hartmann's solution on maternal and cord blood glucose. Acta Obstet Gynaecol Scand 1987; 66: 241-3.

27 Peng ATC, Shamsi H H, Blancato LS, Shulman SM, Chervenak $F A$, Castro JL. Euglycemic hydration with dextrose $1 \%$ in lactated Ringer's solution during epidural anesthesia for cesarean section. Reg Anesth $1987 ; 12: 184-7$.

28 Kenepp NB, Kumar S, Shelley WC, Stanley CA, Gabbe $S G$, Gutsche $B B$. Fetal and neonatal hazards of maternal hydration with $5 \%$ dextrose before caesarean section. Lancet 1982; i: 1150-2. 